\title{
Manganese-Enhanced MRI in Patients with Multiple Sclerosis
}

\author{
(DD.J. Suto, (D) N. Nair, DD.M. Sudarshana, (D) S.U. Steele, (D). Dwyer, DE.S. Beck, (D). Ohayon, (DH. McFarland, (D)A.P. Koretsky, \\ (DI.C.M. Cortese, and DD.S. Reich
}

it $\mathrm{O} \equiv \mathrm{R}$

\begin{abstract}
BACKGROUND AND PURPOSE: Cellular uptake of the manganese ion, when administered as a contrast agent for MR imaging, can noninvasively highlight cellular activity and disease processes in both animals and humans. The purpose of this study was to explore the enhancement profile of manganese in patients with multiple sclerosis.
\end{abstract}

MATERIALS AND METHODS: Mangafodipir is a manganese chelate that was clinically approved for MR imaging of liver lesions. We present a case series of 6 adults with multiple sclerosis who were scanned at baseline with gadolinium, then injected with mangafodipir, and followed at variable time points thereafter.

RESULTS: Fourteen new lesions formed during or shortly before the study, of which 10 demonstrated manganese enhancement of varying intensity, timing, and spatial pattern. One gadolinium-enhancing extra-axial mass, presumably a meningioma, also demonstrated enhancement with manganese. Most interesting, manganese enhancement was detected in lesions that formed in the days after mangafodipir injection, and this enhancement persisted for several weeks, consistent with contrast coming from intracellular uptake of manganese. Some lesions demonstrated a diffuse pattern of manganese enhancement in an area larger than that of both gadolinium enhancement and T2-FLAIR signal abnormality.

CONCLUSIONS: This work demonstrates the first use of a manganese-based contrast agent to enhance MS lesions on MR imaging. Multiple sclerosis lesions were enhanced with a temporal and spatial profile distinct from that of gadolinium. Further experiments are necessary to uncover the mechanism of manganese contrast enhancement as well as cell-specific uptake.

ABBREVIATION: RRMS = relapsing-remitting MS

M ultiple sclerosis causes focal inflammatory demyelinating lesions in the central nervous system, with variable axonal destruction and remyelination. ${ }^{1} \mathrm{MR}$ imaging is commonly used in MS to monitor disease activity and response to treatment, but MR imaging can also be used to investigate lesion

Received March 15, 2020; accepted after revision May 31

From the National Institute of Neurological Disorders and Stroke, National Institutes of Health, Bethesda, Maryland.

This study was supported by the Intramural Research Program of the National Institute of Neurological Disorders and Stroke (Z01 NS003119).

Paper previously presented as an oral presentation at: Congress of the European Committee for Treatment and Research in Multiple Sclerosis, September 11-13, 2019; Stockholm, Sweden.

Please address correspondence to Daniel S. Reich, MD, PhD, Translational Neuroradiology Section, National Institute of Neurological Disorders and Stroke/ National Institutes of Health, 10 Center Dr, MSC 1400, Building 10, Room 5C103,

Bethesda, MD 20892; e-mail: daniel.reich@nih.gov

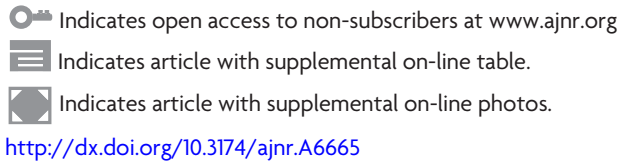

pathophysiology. ${ }^{2}$ Contrast-enhanced MR imaging is the criterion standard for the detection of acute disease activity. Gadolinium chelates are the most commonly used MR imaging contrast agents to detect new lesions when the $\mathrm{BBB}$ is disrupted, resulting in leakage of gadolinium into the parenchyma. However, exploration of other contrast agents with different mechanisms of action offers the potential for additional insights into disease pathophysiology.

MS lesions are believed to form in a complicated series of immune cell interactions that combine to cause demyelination and cell death. ${ }^{3}$ Blood-derived macrophages play a key role in this process and have been shown by histopathologic techniques to be abundant in early lesions. ${ }^{4}$ Despite our evolving understanding of the cellular and biochemical stages of an MS lesion, current imaging techniques lack the ability to finely monitor this development. ${ }^{3}$ Additionally, gadolinium chelates, which are confined to the intravascular and interstitial compartments, are limited to detecting changes in vascular permeability and are unable to directly probe intracellular processes. 


\begin{tabular}{lccclcc}
\hline Participant & Age (yr) & Sex & $\begin{array}{c}\text { MS } \\
\text { Phenotype }\end{array}$ & \multicolumn{1}{c}{ Current Disease-Modifying Therapy } & $\begin{array}{c}\text { Years Since } \\
\text { Symptom Onset }\end{array}$ \\
\hline 1 & 38 & M & RRMS & None & 1 & $<1$ \\
2 & 42 & F & RRMS & Dimethyl fumarate & 1.5 & 5 \\
3 & 32 & F & RRMS & None & 0 & $<1$ \\
4 & 40 & F & RRMS & Interferon $\beta$-la & 3 & 6 \\
5 & 33 & F & RRMS & Daclizumab & 2 & 15 \\
6 & 39 & M & SPMS & Autologous stem cell transplant, conditioning with & 6 & 13 \\
& & & & cyclophosphamide and rituximab & \\
\hline
\end{tabular}

Note:-SPMS indicates secondary-progressive MS; EDSS, Expanded Disability Status Scale.

Manganese ions $\left(\mathrm{Mn}^{2+}\right)$ are paramagnetic and shorten the T1 relaxation time, allowing the metal to be used as an MR imaging contrast agent. Additionally, manganese acts as a calcium analog and can enter cells through calcium channels. ${ }^{5}$ Due to these dual properties, manganese has been explored in animal models as a surrogate marker for neuroanatomy, cell activity and viability, and neuronal transport. Additionally, like calcium, manganese can be trafficked through axons, released at synapses, and taken up by postsynaptic neurons, allowing tract tracing in animal studies. ${ }^{6-10}$ Despite the focus of the field on neuronal import of manganese, uptake by other cell types is likely, given the ubiquity of calcium channels.

In humans, manganese-enhanced MR imaging has been limited by concerns about free manganese toxicity to cardiac muscle cells. ${ }^{11}$ Mangafodipir, a chelate of manganese and an organic ligand dipyridoxyl diphosphate, was therefore developed to allow safe and tolerable release of manganese via transmetallation with zinc in plasma to lower the risk of cardiotoxicity relative to infusion of manganese salts. ${ }^{12}$ Mangafodipir was approved by the FDA in 1997 as a contrast agent for imaging lesions in the liver and pancreas. However, mangafodipir-enhanced brain MR imaging in humans has received little attention. In a recent study, we described a typical pattern of enhancement of manganese in the choroid plexus, anterior pituitary gland, and exocrine glands (including lacrimal, submandibular, and parotid glands) in healthy people. ${ }^{13}$ We found no evidence on MR imaging of manganese enhancement within the brain parenchyma in these subjects, suggesting that mangafodipir is unable to cross the BBB. We established a peak of enhancement in the anterior pituitary gland between 1 and 24 hours and a peak of choroid plexus enhancement at 1.5 hours. Both the spatial and the temporal enhancement profiles of these structures are consistent with studies that infused manganese salts into animals, suggesting that the contrast seen was due to released manganese. ${ }^{14}$

The intracellular uptake characteristics of manganese, as gleaned from animal studies, offer the potential to expand our understanding of cellular activity and viability in active, demyelinating lesions in vivo. Thus, using a 1-time, single-dose injection of mangafodipir, we explored manganese enhancement of lesions in the brain in adults with MS.

\section{MATERIALS AND METHODS}

Six adults with MS (4 women) were recruited under an institutional review board-approved protocol (NCT01326715) from April 2015 to February 2019, after confirming no stated history of excessive manganese exposure, inadequate hepatic or biliary function, or contraindications to MR imaging. The average age was $37 \pm 3.9$ years; the median Expanded Disability Status Scale score was 2 (range, 0-6), and median years since MS symptom onset was 7 (range, $0-15$ ) (Table).

\section{MR Imaging Acquisition and Mangafodipir Administration}

All prospective participants were imaged at baseline with gadolinium (gadobutrol, $0.1 \mathrm{mmol} / \mathrm{kg}$ ) no more than 1 week before mangafodipir injection to assess evidence of a disrupted BBB and to exclude individuals with $>5$ enhancing lesions (a prespecified safety measure). Mangafodipir was reformulated from a clinicalgrade stock under an FDA investigational new drug application, because commercial mangafodipir is no longer produced or marketed. For 1 minute, $5 \mu \mathrm{mol} / \mathrm{kg}$ of mangafodipir was administered intravenously. Five of the 6 participants were imaged within 4 hours of mangafodipir injection; one was first scanned 3 days after injection. Subsequent scans were obtained at variable points within the days to weeks after injection, on the basis of our initial experience in healthy volunteers, participant availability, and an intention to sample a range of postinjection time points in this pilot study. Because manganese (unlike gadolinium) enters cells, we expected slower washout than with gadolinium. All participants underwent a 1-month post-mangafodipir injection MR imaging to assess for persistent signal change in the brain; if found, monthly scans were obtained until residual enhancement resolved.

Images were acquired on a 3T Magnetom Skyra (Siemens) scanner with a 32-channel head coil. Several T1- and T2-weighted sequences were acquired, including a 3D T1 sampling perfection with application-optimized contrasts by using different flip angle evolution (SPACE sequence; Siemens) (0.67-mm isotropic resolution, $\mathrm{TR}=700 \mathrm{~ms}, \mathrm{TE}=26 \mathrm{~ms}, \mathrm{FOV}=256 \mathrm{~mm}$, turbo factor $=$ 96, fat suppression $=$ SPectral Attenuated Inversion Recovery), a 3D-T1-weighted gradient-echo sequence $(1 \mathrm{~mm}$ isotropic, $\mathrm{TR}=$ $7.8 \mathrm{~ms}, \mathrm{TE}=3 \mathrm{~ms}, \mathrm{FOV}=256 \mathrm{~mm}$, flip angle $=18^{\circ}$ ), and a $3 \mathrm{D}-$ T2-FLAIR sequence ( 1 - $\mathrm{mm}$ isotropic resolution, $\mathrm{TR}=4800 \mathrm{~ms}$, $\mathrm{TE}=353 \mathrm{~ms}$, FOV $=256 \mathrm{~mm}$ ). No dynamic image series was acquired during postmangafodipir acquisitions.

\section{MR Imaging Processing}

Images from all postmangafodipir time points were cross-sectionally and then longitudinally registered to the baseline T1-gradientecho sequence using 3dAllineate (afni.nimh.nih.gov). Image processing also included inhomogeneity correction with N4 Bias Field Correction (https://simpleitk.readthedocs.io/en/master/link_ N4BiasFieldCorrection_docs.html). ${ }^{15}$ Intensity normalization was 


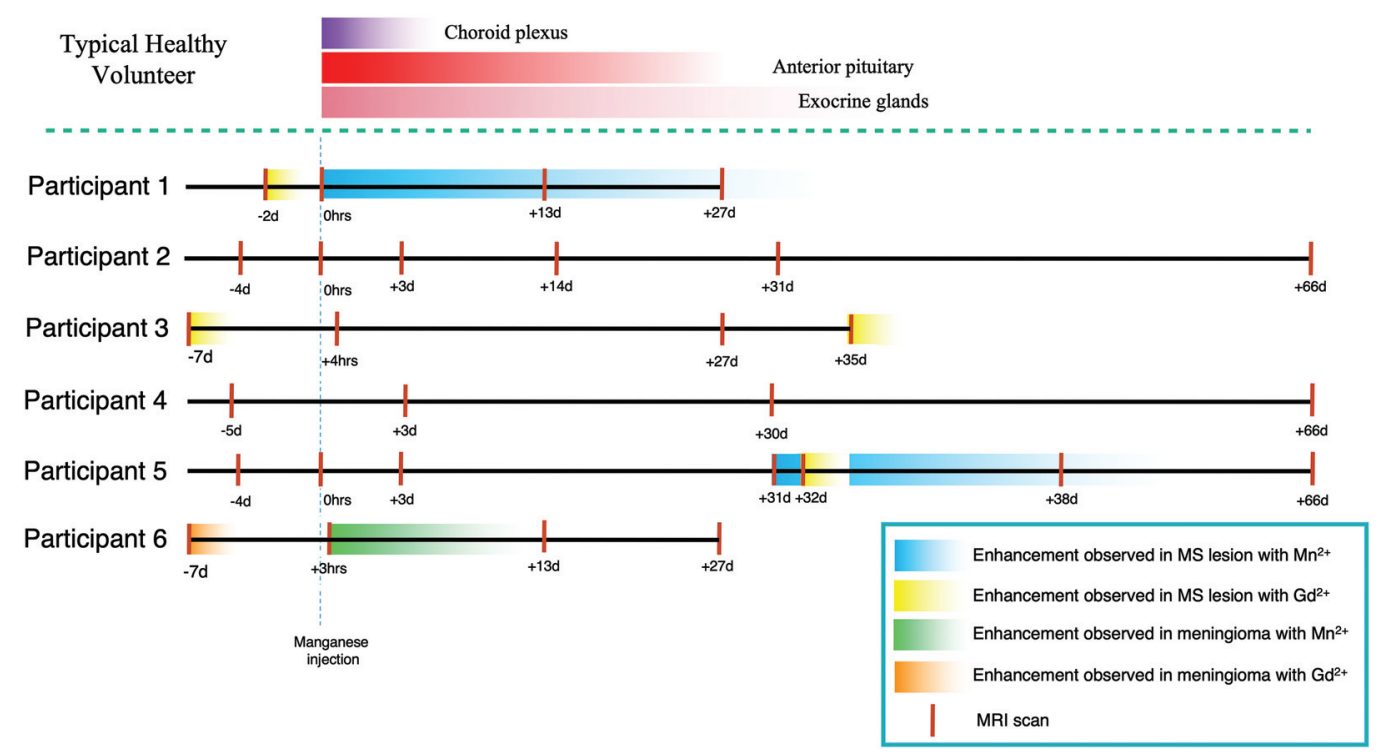

FIG 1. Summary of MR imaging time points and contrast enhancement. Participants were imaged at baseline, shortly after injection, and in the days to months after injection. Red vertical lines indicate MR imaging scans; blue bars, enhancement of MS lesions due to mangafodipir injection; yellow bars, gadolinium enhancement of MS lesions; the green bar, enhancement of a meningioma due to mangafodipir injection; and the orange bar, gadolinium enhancement of a meningioma. Gradients suggest decay of signal between time points but are not intended to be quantitative because temporal granularity is limited by infrequent imaging time points. $\mathrm{D}$ indicates days; $\mathrm{Gd}^{2+}$, gadolinium ion.

achieved by normalizing the whole brain to the median intensity of the skull-stripped brain and subsequently scaling by the maximum intensity. Subtraction images were generated by voxelwise subtraction of the registered, uniformity-corrected, and intensitynormalized T1-SPACE baseline scans from the respective postmangafodipir T1-SPACE images.

\section{RESULTS}

\section{Findings in All Participants}

All participants demonstrated a typical pattern of enhancement in the choroid plexus, anterior pituitary, and exocrine glands, including lacrimal, submandibular, and parotid glands, similar to that in healthy volunteers. ${ }^{13}$

\section{Findings in Specific Participants}

Findings in individual lesions are summarized in Fig 1 and the On-line Table.

\section{Participant 1}

Participant 1 was a 38-year-old man with mild lesion burden and minimally prominent CSF spaces. On baseline MR imaging, there was a large, gadolinium-enhancing lesion in the left periventricular white matter (the lesion that was responsible for his initial MS presentation). Two days later, he was imaged before and within 1 hour after infusion with mangafodipir. This scan demonstrated subtle manganese enhancement in the same lesion (Fig 2C). Central enhancement in this lesion resolved by day 13. No other brain lesions enhanced with mangafodipir. In scans obtained 13 and 27 days postmangafodipir, faint and diffuse enhancement was noted caudal to the lesion border (Fig $2 I,-J,-L,-M$ ).

\section{Participant 2}

Participant 2 was a 42 -year-old woman with relapsing-remitting MS (RRMS), minimally prominent CSF spaces, and a moderate lesion burden. The baseline MR imaging showed no evidence of parenchymal gadolinium enhancement. Images acquired approximately 30 minutes after injection of mangafodipir demonstrated no abnormal enhancement in the brain and no enhancement of previously visualized MS lesions (On-line Fig $1 A-C$ ). Hyperintense T1-weighted signal had resolved in the choroid plexus by 14 days post-mangafodipir injection, similar to prior work on healthy volunteers. All typical manganese-related enhancement had resolved by 38 days postinjection. No new lesions formed during this period.

\section{Participant 3}

Participant 3 was a 32-year-old woman with moderate lesion burden and minimally prominent CSF spaces. Baseline MR imaging 1 week before mangafodipir injection demonstrated 2 small lesions on T2-FLAIR, measuring approximately $4 \times 2$ and $3 \times 2$ $\mathrm{mm}$ in-plane and enhancing faintly with gadolinium. Four hours post-mangafodipir injection, manganese enhancement was not apparent in any MS lesion, regardless of gadolinium enhancement status (On-line Fig 1D-F). Typical mangafodipir-related enhancement in the exocrine glands and choroid plexus resolved by day 27 postmangafodipir. At this time point, the 2 small, previously gadolinium-enhancing lesions were no longer visible on T2-FLAIR. A small new T2-FLAIR lesion had formed, but this did not demonstrate T1-hyperintensity indicative of manganese enhancement. Follow-up imaging 8 days later (35 days post-mangafodipir injection) showed gadolinium enhancement of this new lesion. 


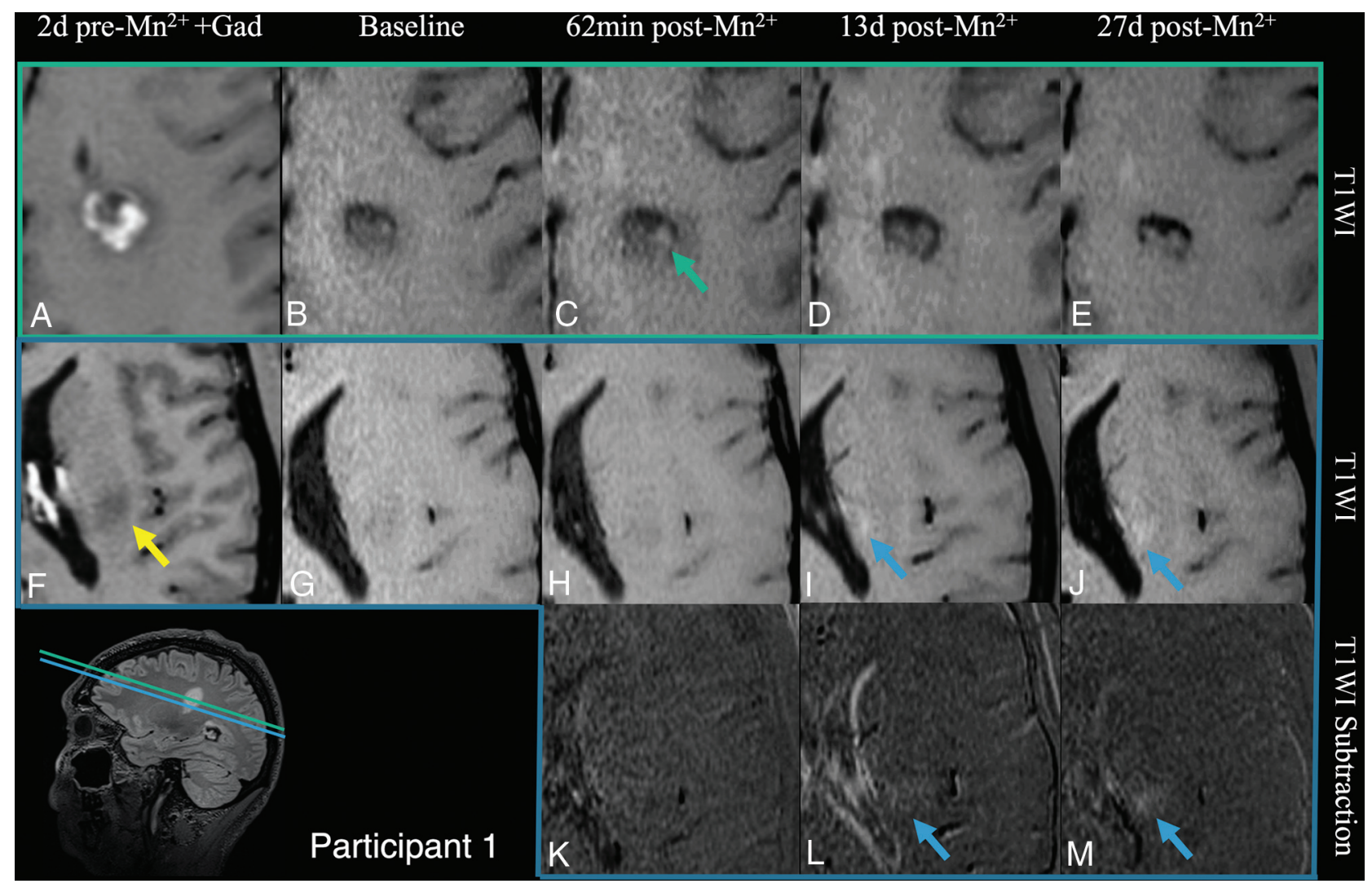

FIG 2. Mangafodipir enhancement of an active gadolinium-enhancing lesion (participant 1). At screening, this lesion enhanced with gadolinium on TT-SPACE ( $A$ ) with caudal edema visible on T1 ( $F$, yellow arrow). At the center of the lesion (green plane, $A-E)$, faint manganese enhancement is noted at 62 minutes $(C)$ and resolved 13 days after injection $(D)$. Caudal to the lesion (blue plane, $F-M)$, manganese enhancement was noted outside the lesion border at 13 days (I, blue arrow) and on subtraction images (L). This enhancement persisted at 27 days (V and $M$, blue arrow). Additionally, ventricular narrowing, which commonly fluctuates, ${ }^{16}$ was noted on day 13 postmangafodipir in reference to the baseline $(L)$; this appeared to resolve by day 27 postmangafodipir.

\section{Participant 4}

Participant 4 was a 40-year-old woman with moderately prominent CSF spaces and moderate lesion burden. The baseline scan showed no abnormal enhancement with gadolinium. On the first postmangafodipir scan 3 days after mangafodipir injection, there was no evidence of enhancement within the brain parenchyma, including in MS lesions. No new lesions developed during the study. All typical manganese enhancement that persisted through 30 days postmangafodipir had resolved by 66 days after mangafodipir injection.

\section{Participant 5}

Participant 5 was a 33-year-old woman with severe lesion burden and moderately prominent CSF spaces. The baseline scan showed no abnormal enhancement with gadolinium. Immediately after mangafodipir injection, there was no abnormal manganese enhancement in the brain and no enhancement of previously visualized MS lesions. MR imaging was repeated 3 days postmangafodipir injection, no new T2-FLAIR lesions had formed, and there was no manganese enhancement in the brain. At 31 days postinjection, 8 new T2-FLAIR lesions were noted. Of these lesions, all were T1-hyperintense, which was not typical of new MS lesions visualized previously in this individual; this finding suggests that the lesions had taken up $\mathrm{Mn}^{2+}$ between imaging time points.
Three of the lesions demonstrated blush-like enhancement, characterized by a faint and diffuse enhancement pattern covering an area approximately 4 times larger than the T2 lesion (Fig 3, upper part). Five lesions demonstrated a punctate pattern of enhancement. A follow-up scan the next day (32 days postinjection) demonstrated nodular gadolinium enhancement in 5 of the 8 total lesions (Fig 3, middle and lower parts), and the area of gadolinium enhancement was contained within the T2-FLAIR lesion area. At 38 days post-mangafodipir injection, 2 additional new T2-FLAIR lesions had formed. All of this participant's manganese-enhancing lesions are shown in On-line Fig 2. Retrospective review of the day 31 scan showed T1-hyperintense signal in 1 of these lesions (Online Fig 2, lesion 13), suggestive of manganese uptake before lesion detection on T2-FLAIR.

\section{Participant 6}

Participant 6 was a 39-year-old man with secondary-progressive MS, a moderate lesion burden, and minimally prominent CSF spaces. There were no gadolinium-enhancing MS lesions on baseline MR imaging; however, there was a long-standing extra-axial, dural-based mass anterior to the left temporal lobe, characteristic of meningioma, that was gadolinium-enhancing (Fig 4B, $-F$ ). He was imaged before and 3 hours after mangafodipir injection. The mass enhanced with mangafodipir (Fig $4 C,-G$ ), but none of the 


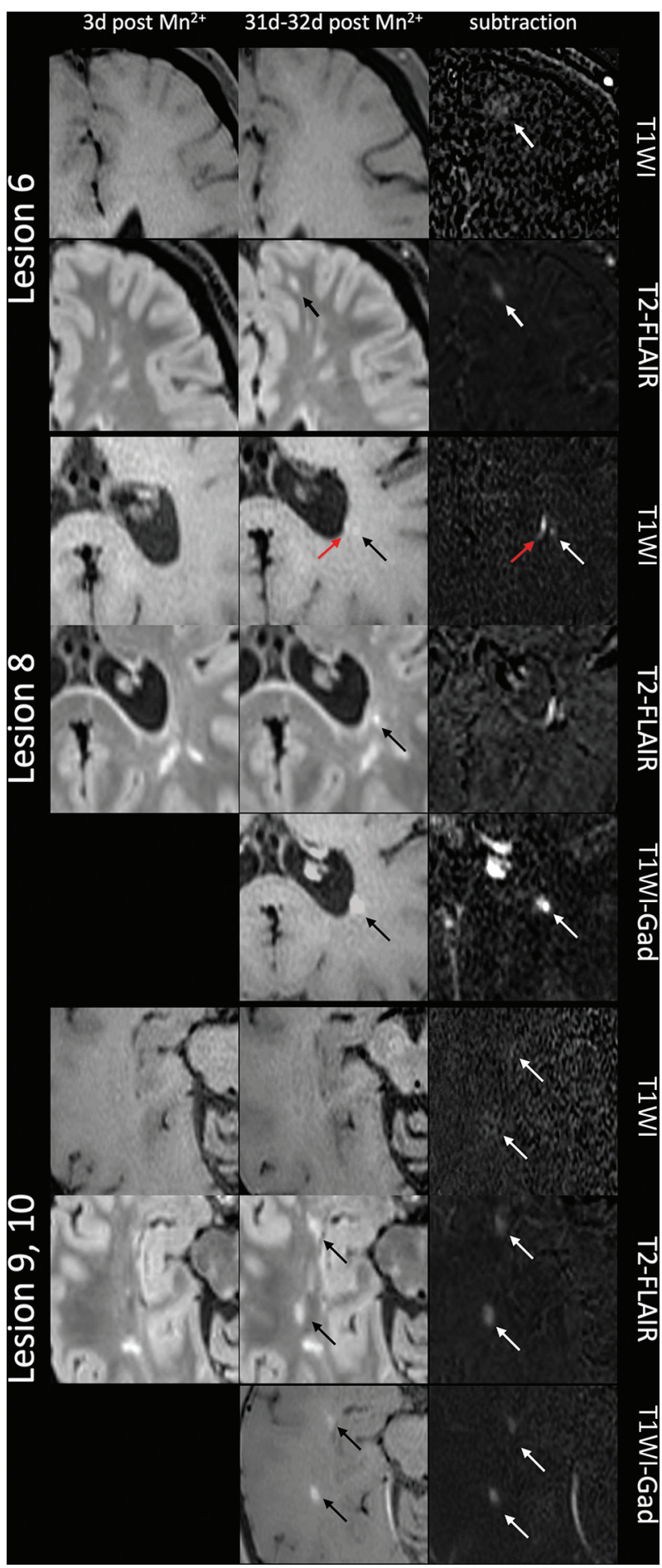

FIG 3. Mangafodipir enhancement of MS lesions (participant 5). Upper part, Lesion 6 showed blush-like mangafodipir enhancement in a T2 lesion that formed between days 3 and 31 post-mangafodipir injection. There is subtle T-hyperintense signal visible only on subtraction, suggesting manganese enhancement, in an area larger than the T2-FLAIR lesion. This lesion did not enhance with gadolinium on day 32 post-mangafodipir injection. Middle, lower part, Several lesions that formed between day 3 and day 31 post-mangafodipir injection enhanced with both manganese and gadolinium. Lesion 8 (middle) demonstrates nodular (black arrow) and ependymal (red arrow) enhancement with manganese but only nodular enhancement with gadolinium. Lesions 9 and 10 (lower part) demonstrate blush-like enhancement with manganese, visible on subtraction images, and nodular enhancement with gadolinium. Gad indicates gadolinium.
MS lesions enhanced. Enhancement in the mass had resolved by the next scan, 13 days post-mangafodipir injection (Fig 4D, $-H$ ).

\section{DISCUSSION}

In this report, we describe the use of a manganese-based contrast agent (mangafodipir) in a series of adults with MS and report that active MS plaques enhance with manganese in patterns distinct from those of gadolinium enhancement in the same lesions. Although variable delays between mangafodipir infusion and imaging limit direct comparison across the participants in our study, several patterns emerged. Similar to healthy volunteers, ${ }^{13}$ we found a characteristic pattern of manganese enhancement in the anterior pituitary gland, exocrine glands, and choroid plexus shortly after injection. We did not observe manganese enhancement in chronic MS lesions. One MS lesion that was gadoliniumenhancing 2 days before mangafodipir administration also demonstrated manganese enhancement. Most interesting, some lesions that formed in the days to weeks after mangafodipir injection also enhanced, evident in delayed scans.

With respect to the manganese enhancement pattern, 4 active lesions demonstrated diffuse, blush-like enhancement that encompassed a much larger volume than was hyperintense on either T2-FLAIR or postgadolinium T1 (Fig 3). Considering that we never observed manganese enhancement in areas with intact $\mathrm{BBBs}$, this observation suggests that the manganese ion or mangafodipir entered the brain parenchyma within the lesions, was taken up by local cells or cell processes, and subsequently spread outside the T2-FLAIR area. We cannot resolve whether such uptake was within axons, glia, invading immune cells, or some combination.

In addition to distinct enhancement patterns, the kinetics of manganese enhancement also differ from that of gadolinium. In participant 5, manganese enhancement occurred during a much longer time window than gadolinium enhancement: Lesions newly visible on T2-FLAIR even 38 days after injection demonstrated manganese enhancement. Lesion 13, which was not visible on T2FLAIR 31 days postinjection, showed faint enhancement with manganese at that timepoint. Additionally, this lesion demonstrated gadolinium enhancement the following day, with no T2FLAIR correlate. This result is consistent with published data suggesting that demyelination, which causes hyperintense signal on T2-weighted images, is preceded by other pathologic processes in both $\mathrm{MS}^{17,18}$ and experimental autoimmune encephalomyelitis ${ }^{3,19}$ lesions and that these processes are not entirely invisible to MR imaging. It also suggests that the manganese that is injected with mangafodipir may be retained in various stores within the body (possibly in the liver, kidney, and exocrine/endocrine glands), subsequently re-entering the circulation at low-but-steady levels. This characteristic would allow manganese accumulation within the intracellular compartments in newly forming lesions with damaged BBBs.

Observations in participant 3 further illustrate that manganese enhancement of MS lesions must be interpreted differently from gadolinium enhancement. This participant had 2 small lesions that enhanced with gadolinium at baseline, as well as a newly formed and later gadolinium-enhancing lesion. However, none of these lesions demonstrated evidence of enhancement after mangafodipir. 


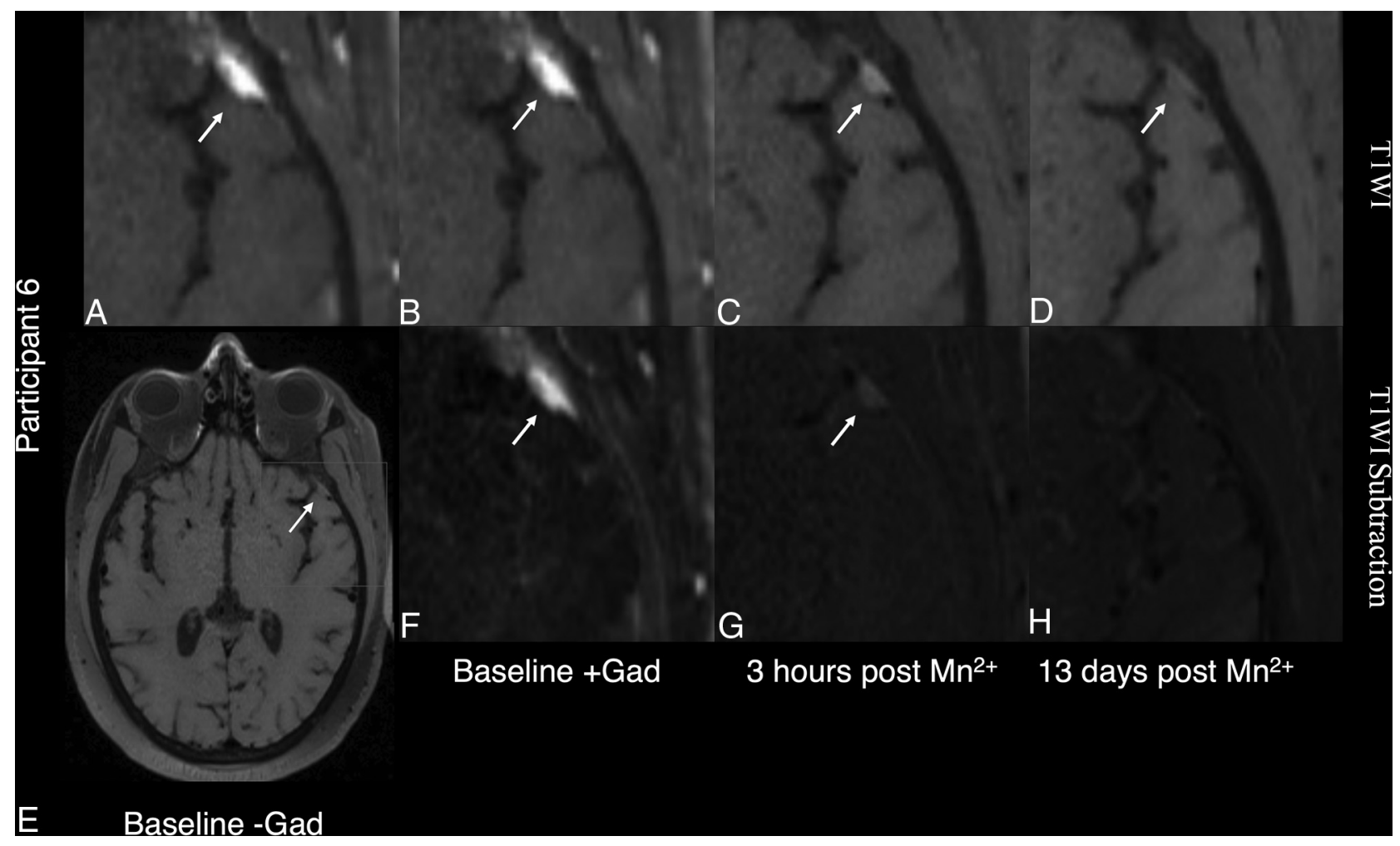

FIG 4. Manganese enhancement of a presumed meningioma in participant 6, a 39-year-old man with secondary-progressive MS. The mass (arrow) is visible on precontrast T7-weighted images ( $A$ and $E$ ) with vivid gadolinium enhancement (gadolinium [Gad]) visible on both T7-weighted $(B)$ and $T 7$ gadolinium subtraction $(F)$ images. Mangafodipir enhancement is visible within the mass 3 hours after mangafodipir ( $C$ and $G$ ) and had resolved by 13 days postinjection $(D$ and $H)$.

It is possible that the small size and faint gadolinium enhancement of these lesions at baseline were below detectability with mangafodipir at the dose we used, but it could also suggest that these lesions were at a late active stage. Additionally, a lesion in this participant that formed after mangafodipir injection did not visibly take up manganese, potentially because the time between manganese injection and lesion formation was too long.

A key difference between manganese and gadolinium in animal studies is the ability of manganese to be imported into cells and, in neurons, transported within axons and across synapses. $^{20}$ The enhancement patterns we observed in MS lesions, though, appear different from those demonstrated in animal models, with no obvious linear enhancement along white matter tracts. ${ }^{21,22}$ It is possible that tract-restricted manganese enhancement was too faint at the FDA-approved dose, which delivers a much lower manganese load than is typically given in animal experiments. ${ }^{11,23}$ PET imaging with manganese-52 $\left(\mathrm{Mn}^{2+}\right)$ might overcome this limitation at the expense of spatial resolution. ${ }^{24}$

In addition to the observed manganese enhancement in MS lesions, participant 6 had a presumed meningioma that enhanced 3 hours following mangafodipir injection. The meningioma also avidly enhanced with gadolinium, but unlike with gadolinium, mangafodipir enhancement was not masked by nearby vascular enhancement. Manganese enhancement had resolved by the next scan 13 days later. Although mangafodipir has been previously shown to be equal or better at detecting liver lesions and metastases than contrast-enhanced CT and ferucarbotran-enhanced MR imaging, its use in meningiomas has not been reported. ${ }^{25-28}$ One study reported that manganese retention in hepatocellular carcinoma correlates with tumor staging and prognosis, ${ }^{29}$ and it is possible that patterns of manganese enhancement could also provide useful clinical information about intracranial tumors.

\section{CONCLUSIONS}

This is the first study to evaluate enhancement dynamics of manganese within MS lesions. Our data show that manganese ions enable visualization of the acute inflammatory demyelination that occurs in active MS lesions. Furthermore, the intracellular capability of manganese is consistent with diffuse enhancement in an area larger than that of the T2-FLAIR lesion days after injection. From the results in this small cohort, we cannot comment on differences in enhancement patterns that may be induced by disease-modifying therapies. Most important, we cannot distinguish between enhancement due to $\mathrm{Mn}^{2+}$ ions and mangafodipir at early time points because these may generate similar enhancement profiles. However, transmetallation of mangafodipir increases the likelihood that enhancement at later time points is due to the ion 
itself. While mangafodipir used at the dose in this study does not fully recapitulate the ability of gadolinium to vividly and immediately mark active MS lesions, use of mangafodipir in MS imaging offers the possibility of following lesion formation in a longer window than gadolinium and may provide new insights into the pathophysiology of lesion formation.

\section{ACKNOWLEDGMENTS}

We thank the National Institute of Neurological Disorders and Stroke Neuroimmunology Clinic and the Clinical Trials Unit (in particular Rosalind Hayden, Rosemarie Cuento, and Sandra Martin), National Institutes of Health Pharmaceutical Development Section (especially Gopal Potti and Judith Starling), Dzung Pham, John Olson, and the Functional MR Imaging Facility for their assistance.

Disclosures: Daniel J. Suto-RELATED: Grant: National Institutes of Health Internal Funding, Comments: National Institute of Neurological Disorders and Stroke Z01 NS003119*; Support for Travel to Meetings for the Study or Other Purposes: Congress of the European Committee for Treatment and Research in Multiple Sclerosis; Provision of Writing Assistance, Medicines, Equipment, or Administrative Support: National Institute of Neurological Disorders and Stroke Z01 NS003119*; UNRELATED: Employment: National Institutes of Health, Comments: National Institutes of Health Postbaccalaureate Program.* Erin S. Beck-RELATED: Grant: National Multiple Sclerosis Society, Comments: fellowship grant to support my salary.* Henry McFarland-UNRELATED: Employment: Scientific Director of the Cummings Foundation, Comments: not-for-profit educational foundation; Royalties: daclizumab (Biogen through the National Institutes of Health), Comments: $<\$ 100$ in 2019. Alan P. Koretsky - RELATED: Grant: I am an Intramural Investigator at the National Institute of Neurological Disorders and Stroke, National Institutes of Health; Congress allocated money to the National Institute of Neurological Disorders and Stroke that was used to support this work; however, we do not refer to this support as a grant; UNRELATED: Patents (Planned, Pending or Issued): The National Institute of Neurological Disorders and Stroke supports patents for intramural investigators. I do have some patents pending, but there is no money to me or the National Institutes of Health; these are not related in any way to the submitted work; Travel/Accommodations/Meeting Expenses Unrelated to Activities Listed: Typically, travel is reimbursed when Intramural Investigators give academic presentations at universities or relevant meetings. No money is paid to me or the National Institutes of Health for these presentations. In addition, I serve on a couple of advisory committees (no compensation to me or the National Institutes of Health), for which travel is paid. Daniel S. ReichUNRELATED: Expert testimony: Leventhal and Puga LLC, Bounds Law Group LLC; Grants/Grants Pending: Vertex Pharmaceuticals.* *Money paid to the institution.

\section{REFERENCES}

1. Reich DS, Lucchinetti CF, Calabresi PA. Multiple sclerosis. $N$ Engl J Med 2018;378:169-80 CrossRef Medline

2. Filippi M, Rocca MA, Barkhof F, et al; Attendees of the Correlation between Pathological MRI Findings in MS Workshop. Association between pathological and MRI findings in multiple sclerosis. Lancet Neurol 2012;11:349-60 CrossRef Medline

3. Absinta M, Sati P, Reich DS. Advanced MRI and staging of multiple sclerosis lesions. Nat Rev Neurol 2016;12:358-68 CrossRef Medline

4. Henderson AP, Barnett MH, Parratt JD, et al. Multiple sclerosis: distribution of inflammatory cells in newly forming lesions. Ann Neurol 2009;66:739-53 CrossRef Medline

5. Silva AC, Bock NA. Manganese-enhanced MRI: an exceptional tool in translational neuroimaging. Schizophr Bull 2008;34:595-604 CrossRef Medline

6. Stieltjes B, Schlüter M, Didinger B, et al. Diffusion tensor imaging in primary brain tumors: reproducible quantitative analysis of corpus callosum infiltration and contralateral involvement using a probabilistic mixture model. Neuroimage 2006;31:531-42 CrossRef Medline

7. Walder N, Petter-Puchner AH, Brejnikow M, et al. Manganese enhanced magnetic resonance imaging in a contusion model of spinal cord injury in rats: correlation with motor function. Invest Radiol 2008;43:277-83 CrossRef Medline

8. Lee JH, Silva AC, Merkle H, et al. Manganese-enhanced magnetic resonance imaging of mouse brain after systemic administration of $\mathrm{MnCl} 2$ : dose-dependent and temporal evolution of T1 contrast. Magn Reson Med 2005;53:640-48 CrossRef Medline

9. Monosov IE, Leopold DA, Hikosaka O. Neurons in the primate medial basal forebrain signal combined information about reward uncertainty, value, and punishment anticipation. I Neurosci 2015;35:7443-59 CrossRef Medline

10. Van Meir V, Pavlova D, Verhoye M, et al. In vivo MR imaging of the seasonal volumetric and functional plasticity of song control nuclei in relation to song output in a female songbird. Neuroimage 2006;31:981-92 CrossRef Medline

11. Crossgrove J, Zheng W. Manganese toxicity upon overexposure. NMR Biomed 2004;17:544-53 CrossRef Medline

12. Toft KG, Hustvedt SO, Grant D, et al. Metabolism and pharmacokinetics of MnDPDP in man. Acta Radiol 1997;38(4 Pt 2):677-89 CrossRef Medline

13. Sudarshana DM, Nair G, Dwyer JT, et al. Manganese-enhanced MRI of the brain in healthy volunteers. AJNR Am J Neuroradiol 2019;40:1309-16 CrossRef Medline

14. Aoki I, Wu YJ, Silva AC, et al. In vivo detection of neuroarchitecture in the rodent brain using manganese-enhanced MRI. Neuroimage 2004;22:1046-59 CrossRef Medline

15. Tustison NJ, Avants BB, Cook PA, et al. N4ITK: improved N3 Bias correction. IEEE Trans Med Imaging 2010;29:1310-20 CrossRef Medline

16. Nakamura K, Brown RA, Narayanan S, et al. Diurnal fluctuations in brain volume: statistical analyses of MRI from large populations. Neuroimage 2015;118:126-32 CrossRef Medline

17. Absinta M, Nair G, Sati P, et al. Direct MRI detection of impending plaque development in multiple sclerosis. Neurol Neuroimmunol Neuroinflamm 2015;2:e145 CrossRef Medline

18. Goodkin DE, Rooney WD, Sloan R, et al. A serial study of new MS lesions and the white matter from which they arise. Neurology 1998;51:1689-97 CrossRef Medline

19. Maggi P, Macri SM, Gaitán MI, et al. The formation of inflammatory demyelinated lesions in cerebral white matter. Ann Neurol 2014;76:594-608 CrossRef Medline

20. Pautler RG. In vivo, trans-synaptic tract-tracing utilizing manganese-enhanced magnetic resonance imaging (MEMRI). NMR Biomed 2004;17:595-601 CrossRef Medline

21. Saleem KS, Pauls JM, Augath M, et al. Magnetic resonance imaging of neuronal connections in the macaque monkey. Neuron 2002;34:685700 CrossRef Medline

22. Chuang $\mathrm{KH}$, Lee JH, Silva AC, et al. Manganese enhanced MRI reveals functional circuitry in response to odorant stimuli. Neuroimage 2009;44:363-72 CrossRef Medline

23. Wolf GL, Baum L. Cardiovascular toxicity and tissue proton T1 response to manganese injection in the dog and rabbit. $A J R A m \mathrm{~J}$ Roentgenol 1983;141:193-97 CrossRef Medline

24. Saar G, Millo C, Szajek L, et al. Anatomy, functionality, and neuronal connectivity with manganese radiotracers for positron emission tomography. Mol Imaging Biol 2018;20:562-74 CrossRef Medline

25. Kim HJ, Kim KW, Byun JH, et al. Comparison of mangafodipir trisodium- and ferucarbotran-enhanced MRI for detection and characterization of hepatic metastases in colorectal cancer patients. AJR Am J Roentgenol 2006;186:1059-66 CrossRef Medline

26. Oudkerk M, Torres CG, Song B, et al. Characterization of liver lesions with mangafodipir trisodium-enhanced MR imaging: 
multicenter study comparing MR and dual-phase spiral CT. Radiology 2002;223:517-24 CrossRef Medline

27. Choi JY, Kim MJ, Kim JH, et al. Detection of hepatic metastasis: manganese- and ferucarbotran-enhanced MR imaging (in French). Eur J Radiol 2006;60:84-90 CrossRef Medline

28. Beziat C, Pilleul F, Yzebe D, et al. Detection of liver metastases in colorectal cancer on chemotherapy: comparative study between MRI with Teslascan and computed tomography with intravenous contrast media. J Radiol 2004;85:307-11 CrossRef Medline

29. Sutcliffe RP, Lewis D, Kane PA, et al. Manganese-enhanced MRI predicts the histological grade of hepatocellular carcinoma in potential surgical candidates. Clin Radiol 2011;66:237-43 CrossRef Medline 